\title{
Anandamide-Evoked Activation of Vanilloid Receptor 1 Contributes to the Development of Bladder Hyperreflexia and Nociceptive Transmission to Spinal Dorsal Horn Neurons in Cystitis
}

\author{
Paulo Dinis, ${ }^{1,5 *}$ Ana Charrua, ${ }^{1,2 *}$ Antonio Avelino, ${ }^{1,2}$ Mohammed Yaqoob, ${ }^{3}$ Stuart Bevan, ${ }^{3}$ Istvan Nagy, ${ }^{4}$ and \\ Francisco Cruz $^{1,5}$ \\ ${ }^{1}$ Institute of Histology and Embryology, Faculty of Medicine, University of Porto, 4200-319 Porto, Portugal, ${ }^{2}$ Institute for Molecular and Cell Biology, \\ University of Porto, 4150-180 Porto, Portugal, ${ }^{3}$ Novartis Institute for Medical Sciences, London WC1E 6BN, United Kingdom, ${ }^{4}$ Department of Anaesthetics \\ and Intensive Care, Faculty of Medicine, Imperial College London, Chelsea and Westminster Hospital, London SW10 9NH, United Kingdom, and \\ ${ }^{5}$ Department of Urology, Hospital São João, 4200-319 Porto, Portugal
}

The role of anandamide in the development of inflammatory hyperalgesia and visceral hyperreflexia was studied in the rat urinary bladder. Animals were given intraperitoneal cyclophosphamide injection, which evokes painful hemorrhagic cystitis accompanied by increased bladder reflex activity. The vanilloid receptor 1 [transient receptor potential vanilloid 1 (TRPV1)] antagonist capsazepine, applied onto the serosal surface of bladders, significantly reduced the hyperreflexia. Mass spectrometric analysis revealed that cyclophosphamide injection significantly and persistently increased the anandamide content of bladder tissues. The increase in the anandamide content paralleled the development of reflex hyperactivity. Anandamide (1-100 $\mu \mathrm{M})$, applied onto the serosal surface of naive bladders, increased the reflex activity in a concentration-dependent manner. Repeated anandamide applications did not produce desensitization of the response. The anandamide-evoked effect was blocked by capsazepine or by instillation of resiniferatoxin, the ultrapotent TRPV1 agonist, into the bladders $24 \mathrm{hr}$ before the anandamide challenge. The cannabinoid 1 receptor antagonist SR141716A [ $N$-piperidino-5-(4-chlorophenyl)-1-(2,4-dichlorophenyl)-4-methylpyrazole-3-carboxamide] significantly increased the potency of anandamide in enhancing bladder reflex activity in naive but not in cyclophosphamide-injected animals. Application of the fatty acid amide hydrolyze inhibitor palmitoylisopropylamine onto the serosal surface of bladders also increased the reflex activity both in naive and cyclophosphamide-injected rats. This latter effect in naive animals was blocked by capsazepine and by resiniferatoxin pretreatment. Finally, intravesical instillation of anandamide $(50 \mu \mathrm{M})$ increased c-fos expression in the spinal cord, which was reduced by capsazepine or by resiniferatoxin pretreatment.

These results suggest that anandamide, through activating TRPV1, contributes to the development of hyperreflexia and hyperalgesia during cystitis.

Key words: capsaicin; bladder; primary sensory neuron; cyclophosphamide; hyperalgesia; resiniferatoxin

\section{Introduction}

The fatty acid amide anandamide activates two receptors on nociceptive primary sensory neurons, the inhibitory cannabinoid 1 (CB1) receptor and the excitatory vanilloid receptor 1 [transient receptor potential vanilloid 1 (TRPV1)] (Devane et al., 1992; Zygmunt et al., 1999; Ahluwalia et al., 2003b; Akerman et al., 2004; Evans et al., 2004). The CB1 receptor and TRPV1 are coex-

\footnotetext{
Received July 3, 2004; revised Nov. 3, 2004; accepted Nov. 3, 2004.

This work was funded by the Fundação Ciência e Tecnologia Project Programa Operacional Ciência, Tecnologia Inovação 32466/Neurociências e Sistemas Endócrinos 2000 and by the Fonds Européen de Développement Régional. *P.D. and A.C. contributed equally to this work.

Correspondence should be addressed to Prof. Francisco Cruz, Department of Urology, Hospital São João, Alameda Hernāni Monteiro, 4200-319 Porto, Portugal. E-mail: cruzfjmr@med.up.pt. DOI:10.1523/JNEUROSCI.2657-04.2004

Copyright $\odot 2004$ Society for Neuroscience $\quad$ 0270-6474/04/2411253-11\$15.00/0
}

pressed by a significant proportion of nociceptive primary sensory neurons, which innervate both somatic and visceral tissues (Guo et al., 1999; Ahluwalia et al., 2000; Avelino et al., 2002; MacNaughton et al., 2004). The excitatory target of anandamide, TRPV1, is a nonselective cationic channel, which is responsive to various physical and chemical activators such as heat greater than $\sim 43^{\circ} \mathrm{C}$ and vanilloids, including capsaicin, the pungent agent of the chili pepper (Caterina et al., 1997). Activation of TRPV1 results in burning pain sensation and increased reflex activity of organs such as the urinary bladder (Szolcsanyi, 1977; Ishizuka et al., 1994). The lack of development of increased heat sensitivity of inflamed tissues in TRPV1-deficient mice shows that TRPV1 is indispensable for the development of inflammatory heat hyperalgesia (Caterina et al., 2000; Davis et al., 2000). The finding that intravesical instillation of vanilloids, which results in loss of 
TRPV1 immunoreactivity in the bladder (Avelino et al., 2002), blocks inflammation-evoked hyperactivity and spinal c-fos overexpression further suggests that TRPV1 could also be pivotal in the development of visceral inflammatory hyperreflexia and hyperalgesia (Hunt et al., 1987; Vizzard, 2000; Dinis et al., 2004).

Although anandamide acting at the CB1 receptor reduces TRPV1-mediated excitation in primary sensory neurons (Richardson et al., 1998; Ahluwalia et al., 2003b; Akerman et al., 2004), recent data suggest that in inflammatory conditions, anandamide could contribute to the development of hyperalgesia and hyperreflexia by activating TRPV1. Although in physiological conditions, the excitatory effect of anandamide on primary sensory neurons is weak, it is significantly increased when inflammatory conditions are replicated in primary sensory neuronal cultures by activating protein kinase A (PKA), protein kinase $\mathrm{C}$ (PKC), or phospholipase C (PLC) (Malmberg et al., 1997; Zygmunt et al., 1999; Chuang et al., 2001; Ahluwalia et al., 2003b; Zhou et al., 2003). Moreover, $\mathrm{Ca}^{2+}$ influx into capsaicin-sensitive primary sensory neurons, which occurs in inflammation (Linhart et al., 2003), results in the production of anandamide, the amount of which is comparable with that evoking TRPV1-mediated excitation of primary sensory neurons after PKA, PKC, and PLC activation in the cells (Premkumar and Ahern, 2000; Chuang et al., 2001; De Petrocellis et al., 2001; Ahluwalia et al., 2003a,b). Anandamide, through TRPV1, evokes action potential generation in capsaicin-sensitive primary afferents (Kollarik and Undem, 2004), which results in pain sensation (Schmelz et al., 2000) and release of neuropeptides, such as substance $\mathrm{P}$, that are essential for the development of inflammatory hyperalgesia and hyperreflexia (Ahluwalia et al., 1994; Lecci et al., 1994a,b; Laird et al., 2000; Hunt and Mantyh, 2001).

Our aim in the present work was to determine whether anandamide contributes to the development of inflammatory hyperreflexia and hyperalgesia. Preliminary results have been published in abstract form (Avelino et al., 2003).

\section{Materials and Methods}

Animals and drugs. All of the experiments were performed in accordance with the revised National Institutes of Health Guide for the Care and Use of Laboratory Animals, with the United Kingdom Animals (Scientific Procedures) Act (1986) and associated guidelines, and with the European Communities Council Directive (86/609/EEC). The use of animals was approved by the animal subjects review board of the University of Porto, Porto, Portugal. Furthermore, all efforts were made to minimize the number of animals used in the present study.

Adult female Wistar rats (250 gm) were obtained from the Gulbenkian Foundation (Porto, Portugal). Anandamide (soy oil:water, 1:4 emulsion), capsaicin, capsazepine, and the fatty acid amide hydrolase (FAAH) inhibitor palmitoylisopropylamide (PIA) were purchased from Tocris Cookson (Bristol, UK). Resiniferatoxin (RTX) and acrolein were purchased from Sigma (Porto, Portugal). Cyclophosphamide was purchased from ASTA Medica (Radebeul, Germany). The CB1 receptor antagonist N-piperidino-5-(4-chlorophenyl)-1-(2,4-dichlorophenyl)-4-methylpyrazole-3carboxamide (SR141716A) was a kind gift from the Chemical Synthesis and Drug Supply Program of the National Institute of Mental Health (Bethesda, $\mathrm{MD}$ ). The stock solution of capsaicin was made in DMSO, whereas that of cyclophosphamide was diluted in saline. Capsazepine, SR141716A, RTX, and PIA stock solutions were made in absolute ethanol. All of the stock solutions were diluted to working concentrations with saline with the exception of PIA, acrolein, and cyclophosphamide for electrophysiological studies. The stock solution of PIA was diluted in 1\% ethanol in saline, whereas acrolein and cyclophosphamide in the patch-clamp recordings were diluted further with the bath solution (see below). The final concentration of soy oil was between 1:48,000 and 1:1200.

Induction of inflammation. Previous findings suggest that TRPV1 plays a pivotal role in the development of inflammatory hyperreflexia and hyperalgesia in cystitis evoked by the anticancer drug cyclophosphamide (Vizzard, 2000; Dinis et al. 2004). Thus, in the present study, we used the well established model of cyclophosphamide-induced bladder inflammation (Cox, 1979) to find out whether anandamide is responsible for the activation of TRPV 1 and contributes to the development of increased bladder reflex activity and pain. Two schedules of intraperitoneal injections were used to produce cystitis: either a single injection of $200 \mathrm{mg} / \mathrm{kg}$ or three injections of $75 \mathrm{mg} / \mathrm{kg}$ each on days 1,4 , and 7 . The singleinjection model was used to assess bladder reflex activity $4 \mathrm{hr}$ after the injection and to measure the anandamide content of the bladders 4, 24, and $72 \mathrm{hr}$ after the injection. The repeated injection model was used to measure the anandamide content of the bladders $8 \mathrm{~d}$ after the first injection. Both treatments produced the same visual signs of inflammation. The bladders were red, swollen, and in some cases, covered by abundant serosal pethechial suffusions. In some animals, the urine contained blood. Control animals received intraperitoneal saline injection(s). These animals had healthy bladders containing normal urine.

Induced desensitization of capsaicin-sensitive bladder afferents. To induce desensitization of TRPV1-expressing bladder afferents, rats were anesthetized with isofluorane (4\% for induction and 2\% for maintenance), and a 26 gauge catheter was inserted into the bladder through the urethra. RTX ( $0.5 \mathrm{ml}$ of $10 \mathrm{~nm})$, which has been shown to desensitize capsaicin-sensitive afferents (Avelino et al., 1999), was then instilled into the bladder through the catheter, and the RTX was left in place for 30 min. After emptying the bladder and rinsing it with saline, animals were left to recover from anesthesia and used $24 \mathrm{hr}$ later for subsequent experiments.

Cystometry and drug application. Bladder reflex activity was studied by cystometry performed under anesthesia with subcutaneous injection of $1.2 \mathrm{mg} / \mathrm{kg}$ urethane. The body temperature was monitored continuously by a rectal thermometer and maintained at $36-37^{\circ} \mathrm{C}$ with a heating pad. Bladders were exposed through a low midline abdominal incision, and a 21 gauge needle was inserted into the bladder dome. Bladders were then left to stabilize for $30 \mathrm{~min}$. Continuous infusion of saline $(6 \mathrm{ml} / \mathrm{hr})$ at $37^{\circ} \mathrm{C}$ was then started while intravesical pressure was continuously monitored with a pressure transducer connected to a personal computer running the Acquire software package (Gould Instruments, Valley View, $\mathrm{OH})$. Bladder contractions could expel the infused saline freely through the urethra.

A silicone plastic tube (inner diameter, $1 \mathrm{~mm}$ ) was placed near the bladder dome, and saline at $37^{\circ} \mathrm{C}$ was continuously applied onto the bladder serosa at a rate of $0.5 \mathrm{ml} / \mathrm{min}$. The number of bladder contractions occurring during a 10 min saline application was taken as the basal bladder reflex activity. Bladder reflex activity was then studied during the application of different drug solutions at $37^{\circ} \mathrm{C}$, with a $0.5 \mathrm{ml} / \mathrm{min}$ rate, onto the serosal surface of the bladders. Drugs were applied for $10 \mathrm{~min}$ except for PIA, which was superfused for $30 \mathrm{~min}$, and SR141716A, which was superfused onto inflamed bladders for $20 \mathrm{~min}$. The excess fluid around the bladders was removed by constant and careful aspiration. Different concentrations of anandamide $(1,5,10,50$, and $100 \mu \mathrm{M})$ were applied onto the bladders successively in a cumulative manner.

Anandamide detection in intact and inflamed bladders. Four hours ( $n=$ $4), 24 \mathrm{hr}(n=4)$, and $3 \mathrm{~d}(n=4)$ after single cyclophosphamide injections, and $24 \mathrm{hr}$ after the last repeated cyclophosphamide injections on the seventh day of the experiment (i.e., on day $8 ; n=4$ ), rats were anesthetized, decapitated, and the bladders were harvested immediately through laparotomy. Bladders of four naive rats and of four animals injected $4 \mathrm{hr}$ previously with saline were also harvested. After removal, bladders were immediately frozen on dry ice and stored at $-80^{\circ} \mathrm{C}$. Frozen bladders were homogenized in water $(1: 5, \mathrm{w} / \mathrm{v})$. The homogenate was extracted with $1 \mathrm{ml}$ of ethyl acetate and then centrifuged at $3000 \times g$ for $10 \mathrm{~min}$. The organic phase was removed, dried under vacuum at $-40^{\circ} \mathrm{C}$, weighed, and redissolved in $100 \mu \mathrm{l}$ of methanol.

Chromatographic separation of anandamide was performed at room temperature in an HPLC mass spectrometer system (HP1100 MSD; Hewlett-Packard, Palo Alto, CA) equipped with a vacuum degasser, autosampler (Hewlett-Packard), and a Phenomenex (Cheshire, UK) C18 reversed-phase column $(3 \mu \mathrm{m} ; 300 \AA ; 30 \times 4.6 \mathrm{~mm})$. Ten microliters of 
the sample were injected into the system, and the flow rate was held constant at $1 \mathrm{ml} / \mathrm{min}$. Under these conditions, the retention time of anandamide was $6.173 \mathrm{~min}$. The column efflux was directly introduced into the ion source of the HP1100 MSD detector. Quantitative analysis was performed by selected ion recording over the respective protonated molecular ions. The peak area was chosen as the chromatographic signal for quantification and integrated automatically using the WinNT ChemStation (Hewlett-Packard) software package.

Standard curves were prepared by spiking bladder homogenate samples originating from control (vehicle-treated) animals with six different concentrations of anandamide as external standard. These were then processed in the same way as the original samples. The calibration set was prepared on the day of analysis, and the standards were run before and after each analytical batch. Samples were compared with the standard curve covering the concentration range of the samples. The standard curves after extraction were linear. The unknown sample concentrations were calculated from the linear regression parameters of the standard curves and expressed in picomoles per gram of dry weight of bladders.

Whole-cell voltage-clamp recordings. Electrophysiological recordings were made from Chinese hamster ovarian $(\mathrm{CHO})$ cells heterologously expressing rat TRPV1. The cell line was generated as described previously (McIntyre et al., 2001). Briefly, a $3.3 \mathrm{~kb}$ ratVR1 cDNA insert was prepared by removing it from the pBK-CMV plasmid with EcoR1 and NotI digestion and ligating it into pIRESneo (Clontech, Cambridge, UK). The VR1-pIRESneo construct was then transfected into a CHO host cell line by Lipofectamine Plus (Invitrogen, San Diego, CA). Cells were maintained in MEM $\alpha$ medium supplemented with $100 \mathrm{U} / \mathrm{ml}$ penicillin, 100 $\mu \mathrm{g} / \mathrm{ml}$ streptomycin, $2 \mathrm{~mm}$ L-glutamine, $10 \%$ fetal calf serum, and 700 $\mu \mathrm{g} / \mathrm{ml}$ geneticin.

Recordings were made using conventional whole-cell voltage-clamp technique with an Axoclamp 200B amplifier using the pClamp7 software package (Axon Instruments, Union City, CA). The composition of the bath and pipette solutions were (in $\mathrm{mm}$ ): $140 \mathrm{NaCl}, 5 \mathrm{KCl}, 1 \mathrm{MgCl}_{2}, 2$ $\mathrm{CaCl}_{2}, 10$ HEPES, 10 glucose, $\mathrm{pH} 7.4$ and $140 \mathrm{KCl}, 1 \mathrm{CaCl}_{2}, 2 \mathrm{MgATP}, 10$ HEPES, 10 EGTA, pH 7.4, respectively. All of the recordings were made at room temperature at a holding membrane potential of $-60 \mathrm{mV}$. Cells were initially tested for capsaicin sensitivity by brief $(5 \mathrm{sec})$ application of capsaicin $(1 \mu \mathrm{M})$. Cyclophosphamide ( $1 \mathrm{nM}, 1 \mu \mathrm{M}$, or $1 \mathrm{~mm}$ ) or acrolein (1 $\mathrm{nM}, 1 \mu \mathrm{M}$, or $1 \mathrm{~mm}$ ) was superfused to the cells in a cumulative manner. Each drug was applied for $5 \mathrm{sec}$ with a $1 \mathrm{~min}$ interval between the different drugs-concentrations. One minute after the application of the highest concentration of acrolein or cyclophosphamide, capsaicin $(1 \mu \mathrm{M})$ was superfused onto the cells again to see whether acrolein or cyclophosphamide had any long-lasting effect on the capsaicin-evoked response.

Spinal c-fos expression. Activation of nociceptive primary sensory neurons resulting in pain-related behavior in animals evokes enhanced c-fos expression in the spinal cord (Hunt et al., 1987). Thus, to find out whether anandamide induces nociceptive transmission to spinal dorsal horn neurons, we studied spinal c-fos expression. To avoid laparotomyinduced spinal c-fos expression, anandamide in this experiment was instilled into the bladder through the urethra. Twelve rats were anesthetized with intraperitoneal $35 \%$ aqueous chloral hydrate $(0.1 \mathrm{ml} / 100 \mathrm{gm})$, and their bladders were catheterized through the urethra with a 26 gauge catheter and emptied. The bladders of four animals were instilled with 0.5 $\mathrm{ml}$ of a $50 \mu \mathrm{M}$ anandamide solution, whereas another four rats received $0.5 \mathrm{ml}$ of saline. To ascertain the role of TRPV1 on the anandamideevoked effect, bladders of four animals were instilled with $0.5 \mathrm{ml}$ of saline containing $50 \mu \mathrm{M}$ anandamide and $50 \mu \mathrm{M}$ capsazepine. In addition, four rats previously desensitized with intravesical RTX also received $0.5 \mathrm{ml}$ of $50 \mu \mathrm{M}$ anandamide. Solutions were left in place for $30 \mathrm{~min}$ and then withdrawn, and the bladders were rinsed with saline.

Two hours after the beginning of the drug application, rats were perfused through the ascending aorta with $100 \mathrm{ml}$ of $0.1 \mathrm{M}$ PBS followed by $1000 \mathrm{ml}$ of $4 \%$ paraformaldehyde in $0.1 \mathrm{~m}$ phosphate buffer, $\mathrm{pH}$ 7.4. The L6 spinal segments were removed and immersed for $2 \mathrm{hr}$ into the same fixative followed by immersion overnight in 30\% sucrose in phosphate buffer. Spinal segments were cut by a freezing microtome into $40 \mu \mathrm{m}$ transverse sections, and one in every three consecutive sections was im-
$\mathbf{A}$

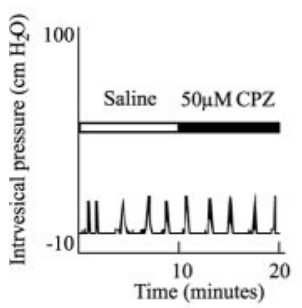

C

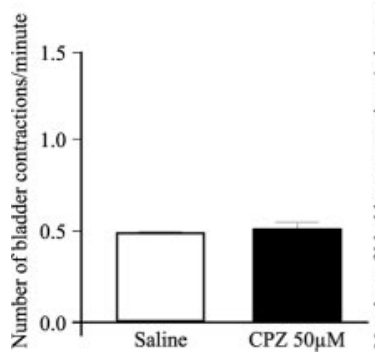

B

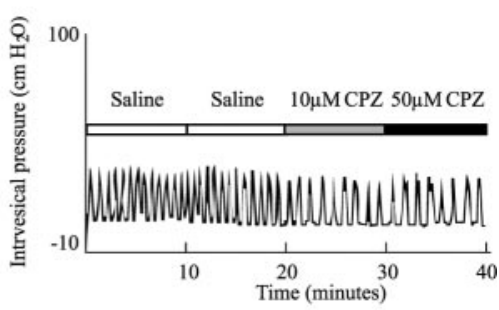

D

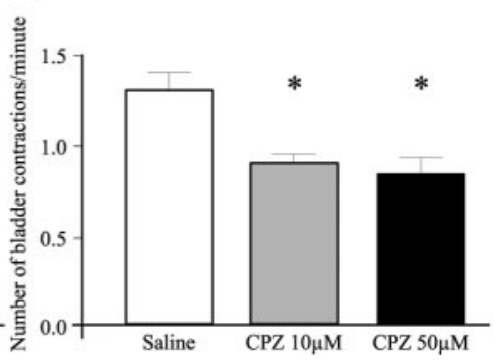

Figure 1. Capsazepine (CPZ) reduces the reflex activity of inflamed bladders only. A, Typical cystometrogram from a naive bladder. The basal reflex activity was determined during a $10 \mathrm{~min}$ period by intravesical perfusion of saline $\left(37^{\circ} \mathrm{C}\right.$ ) and superfusing $37^{\circ} \mathrm{C}$ saline onto the serosal surface of the bladder. Note that $50 \mu \mathrm{m}$ capsazepine did not change the reflex activity of the noninflamed bladder. $B$, Typical cystometrogram from an inflamed bladder $4 \mathrm{hr}$ after intraperitoneal cyclophosphamide injection. Note that the basal reflex activity measured during saline superfusion is significantly higher than that in the naive bladder shown in $A$. In contrast to naive bladders, capsazepine (10 or $50 \mu \mathrm{m}$ ) superfusion onto the serosal surface did reduce the reflex activity significantly. However, $50 \mu \mathrm{m}$ capsazepine did not have greater effect than $10 \mu \mathrm{M} . C$, Average number of bladder contractions in naive bladders $(n=4)$ during saline (empty bar) and during capsazepine (50 $\mu \mathrm{m}$; solid bar) superfusion onto the serosal surface. $D$, Average number of contractions in bladders from animals that received intraperitoneal cyclophosphamide injection 4 hr before the recordings (empty bar; $n=5$ ). Both $10 \mu \mathrm{m}$ (solid gray bar) and 50 $\mu \mathrm{M}$ (solid black bar) capsazepine reduced the enhanced reflex activity significantly. ${ }^{*} p<0.05$. Error bars indicate SEM.

mersed and stored in a cryoprotective solution at $-20^{\circ} \mathrm{C}(\mathrm{Lu}$ and Haber, 1992). After sectioning of spinal cords from all 16 animals, sections were washed with PBS and incubated in the same bath with a polyclonal antiserum against the Fos protein raised in rabbit (diluted at 1:6000; Oncogene Sciences, Uniondale, NY). The immunoreaction was visualized by the ABC-HRP method (Vector Elite kit; Vector Laboratories, Burlingame, CA). Fos-immunoreactive cells in the dorsal horn in 10 sections taken randomly from the spinal cord of each animal were counted.

Data presentation and statistical analysis. Bladder reflex activity was evaluated by calculating the average number of bladder contractions per minute during a $10 \mathrm{~min}$ saline or drug application. The relevant data obtained from four to nine animals were averaged. Mean values of the anandamide concentrations in bladders were calculated from appropriate data of four animals. Spinal c-fos expression was analyzed by calculating the mean of the number of Fos-immunoreactive cells found in 10 sections of each animal. The mean number of Fos-immunopositive cells found in the appropriate four animals was then calculated.

Differences between the effects of various drugs were studied by ANOVA. The significance of the differences between relevant data were established by the post hoc Bonferroni test. Differences were considered significant at $p<0.05$. Data are expressed as mean \pm SEM, and $n$ refers to the number of animals.

\section{Results}

The effect of capsazepine on bladder reflex activity

The baseline bladder reflex activity of naive rats was $0.48 \pm 0.01$ $(n=4)$ contractions per minute (Fig. 1A,C). Capsazepine applied onto the bladders did not produce any change in the 

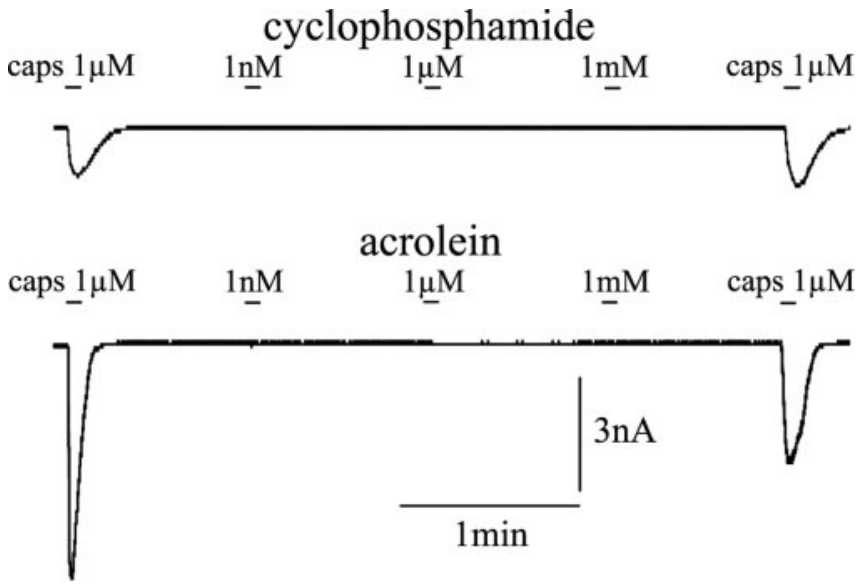

Figure 2. Whole-cell voltage-clamp recordings from TRPV1-expressing $\mathrm{CHO}$ cells challenged by capsaicin (caps), cyclophosphamide (top trace), and acrolein (bottom trace). Recordings were done with physiological pipette and bath solutions at $E_{\mathrm{m}}=-60 \mathrm{mV}$, and drugs were applied for $5 \mathrm{sec}$ with a 1 min interval between the applications. Capsaicin $(1 \mu \mathrm{m})$ evoked inward current in all cells tested. However, neither cyclophosphamide nor acrolein at $1 \mathrm{~nm}, 1$ $\mu \mathrm{M}$, or $1 \mathrm{~mm}$ concentration produced any detectable currents. Furthermore, because $1 \mu \mathrm{m}$ capsaicin applied after the cyclophosphamide or acrolein challenge produced similar responses to the first capsaicin application, neither cyclophosphamide nor acrolein seem to produce sensitization or desensitization of TRPV1-mediated responses. Solid bars above current traces indicate drug applications.

frequency of bladder contractions either at $10 \mu \mathrm{M}$ (data not shown) or $50 \mu \mathrm{M}$ concentrations (Fig. $1 A, C$ ).

Four hours after a single cyclophosphamide injection, the frequency of bladder contractions was significantly higher than that in naive rats $(1.31 \pm 0.1 ; p=0.0004 ; n=5$ ) (Fig. $1 B, D)$. In contrast to the lack of any effect in naive rats, capsazepine produced a significant reduction in the bladder reflex activity in the cyclophosphamide-injected animals both at $10 \mu \mathrm{M}$ (to $0.9 \pm 0.05$; $p=0.004 ; n=5)$ and $50 \mu \mathrm{M}$ (to $0.84 \pm 0.09 ; p=0.003 ; n=5$ ) (Fig. $1 B, D$ ). Although the effect of $50 \mu \mathrm{M}$ capsazepine was somewhat greater than that produced by $10 \mu \mathrm{M}$ capsazepine, the difference was not significant. These findings were in agreement with previous results (Vizzard 2000; Dinis et al., 2004) and indicated that TRPV1 activity contributed to the development of hyperreflexia in cyclophosphamide-induced cystitis. Furthermore, because capsazepine has been shown to compete for the capsaicin-binding site of TRPV1 (Bevan et al., 1992), these findings suggested that TRPV1 might be activated by a ligand(s) binding to that domain of the receptor.

\section{Effect of cyclophosphamide and acrolein on TRPV1}

Although neither cyclophosphamide nor its metabolite acrolein, which is excreted by urine (Cox, 1979), has structural similarity to any of the known vanilloid agonists, it is possible that these agents activate TRPV1 on bladder afferents. Thus, during a search for a probable TRPV1 activator, we examined whether cyclophosphamide or acrolein has any effect on TRPV1. Application of capsaicin $(1 \mu \mathrm{M})$ evoked inward current $(\mathrm{A}=-0.26 \mathrm{nA}$ to $-6.33 \mathrm{nA})$ in all the cells tested $(n=39)$ (Fig. 2). In contrast, neither cyclophosphamide $(n=12)$ nor acrolein $(n=13)$ evoked any current between $1 \mathrm{nM}$ and $1 \mathrm{~mm}$ (Fig. 2). Application of capsaicin after an acrolein or cyclophosphamide challenge evoked inward currents in all cells. In some cells, the response to capsaicin after acrolein or cyclophosphamide application was larger than that seen with the first capsaicin application. However, similar increases were observed without acrolein or cyclo- phosphamide application ( $n=14$; data not shown); therefore, these increases were unrelated to any drug treatment. These results indicated that TRPV1 in bladder afferents was probably activated not by cyclophosphamide or acrolein but by an endogenous ligand.

\section{Anandamide content of intact and inflamed bladders}

Among the known endogenous TRPV1 activators, anandamide binds to TRPV1 at the capsaicin binding site (Jordt and Julius, 2002; Gavva et al., 2004). Thus, we next investigated whether cyclophosphamide injection increased the anandamide content of the urinary bladder. Measurements were done in bladders from naive and saline-injected rats and in bladders from cyclophosphamide-injected animals 4, 24, and $72 \mathrm{hr}$ after a single injection or $8 \mathrm{~d}$ after first of the multiple injections. The anandamide concentrations in the bladders of the naive and the salineinjected animals were similar $(34.6 \pm 3.9 \mathrm{pmol} / \mathrm{gm}$ of dry tissue, $n=4 ; 32.1 \pm 2.8 \mathrm{pmol} / \mathrm{gm}$ of dry tissue, $n=4$, respectively). Therefore, data from these animals were pooled together and used as control data $(33.4 \pm 1.4 \mathrm{pmol} / \mathrm{gm}$ of dry tissue; $n=8)$ (Fig. 3D). Four hours after single $(200 \mathrm{mg} / \mathrm{kg})$ cyclophosphamide injections, the anandamide level of the bladders increased significantly $(45.0 \pm 3.4 \mathrm{pmol} / \mathrm{gm}$ of dry tissue; $p=0.02 ; n=4)$ (Fig. $3 D)$. At $24 \mathrm{hr}$, the anandamide level showed no additional increase. At $72 \mathrm{hr}$, the anandamide content of the bladders reached its highest concentration $(59.28 \pm 7.8 \mathrm{pmol} / \mathrm{gm}$ of dry tissue; $n=$ 4) (Fig. 3D). The anandamide level in the bladders from the animals injected repeatedly on days 1,4 , and 7 was $49.18 \pm 6$ $\mathrm{pmol} / \mathrm{gm}$ of dry tissue $(n=4)$ at $24 \mathrm{hr}$ after the last injection. This value was also significantly higher $(p=0.04)$ than that in the control, untreated bladders (Fig. $3 D$ ). These findings showed that the anandamide concentration of the bladders was persistently elevated in cyclophosphamide-injected rats.

\section{The effect of exogenous anandamide on the micturition reflex activity}

To find out whether the increased anandamide content could be responsible for the increased reflex activity of the bladders observed during cystitis, exogenous anandamide was applied onto the serosal surface of naive bladders, while the intravesical pressure was monitored by cystometry. The basal bladder reflex activity during a $10 \mathrm{~min}$ saline application was $0.51 \pm 0.09$ contractions per minute $(n=8)$. Application of the anandamide vehicle (soy oil in saline between 1:1200 and 1:48,000 dilutions) did not produce any effect on the bladder reflex activity (data not shown). Application of anandamide $(1100 \mu \mathrm{M})$, however, produced a concentration-dependent increase in the number of contractions (Fig. $4 A, B$ ). The lowest concentration of anandamide producing a significant increase in the frequency of contractions was $50 \mu \mathrm{M}(0.73 \pm 0.03$ contractions $/ \mathrm{min} ; p=0.0001 ; n=8)$. One hundred micromolar anandamide produced an additional increase in the activity $(0.79 \pm 0.03$ contractions $/ \mathrm{min} ; p=$ $0.000002 ; n=8)$. This value, however, was not significantly different from that produced by $50 \mu \mathrm{M}$ anandamide. The $\mathrm{EC}_{50}$ of anandamide was $17.8 \pm 2 \mu \mathrm{M}(n=8)$. The effect of anandamide on the reflex activity could be observed within 1 min after the drug reached the surface of the bladders, and the activity remained constant during the $10 \mathrm{~min}$ application.

Prolonged application of TRPV1 agonists induces desensitization of TRPV1 (Szallasi, 2002). As shown in Figure 5A, the first application of $50 \mathrm{~nm}$ RTX onto the bladder surface induced a significant increase in the number of contractions $(0.5$ contractions/min before and 0.9 contractions/min during RTX applica- 


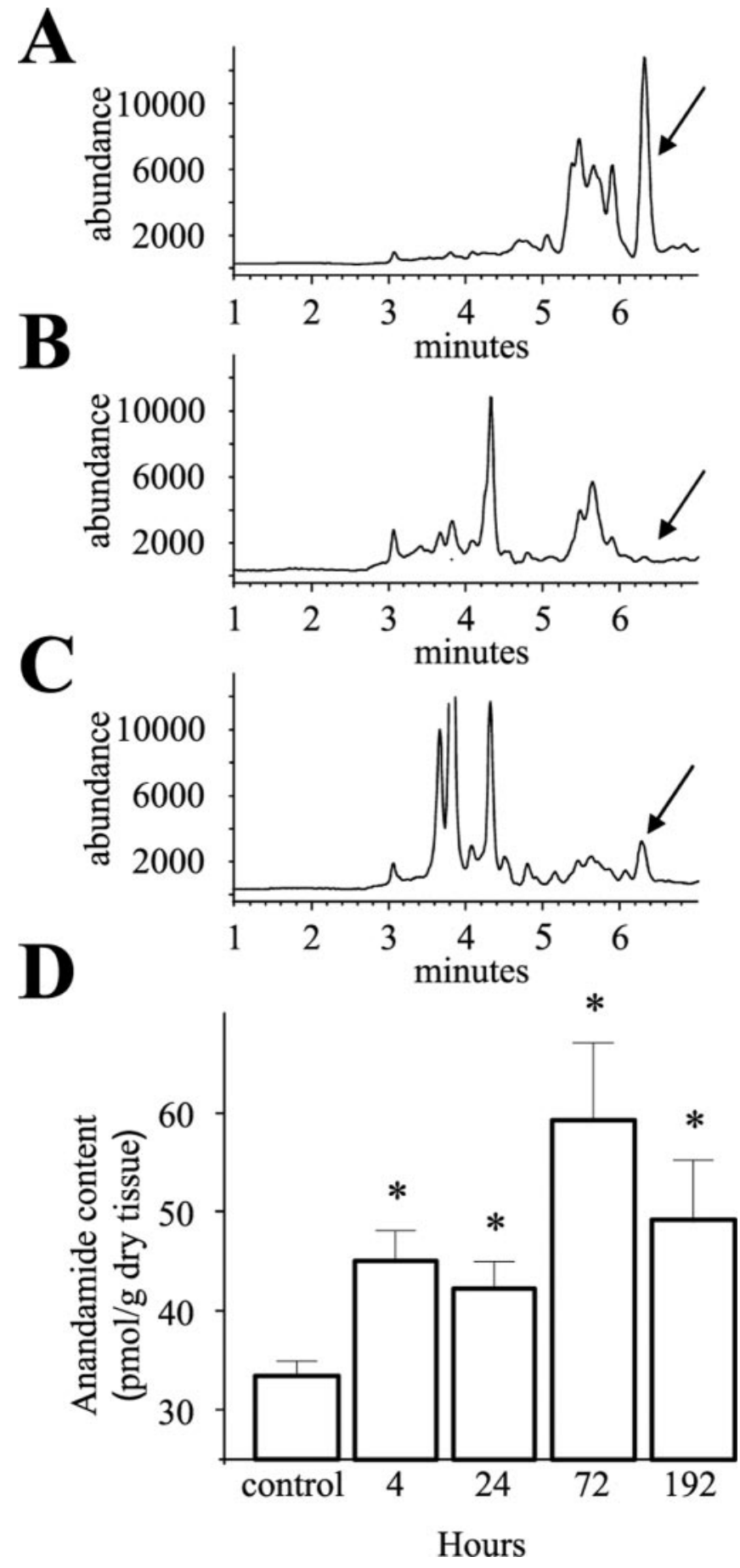

Figure 3. Intraperitoneal cyclophosphamide injection increases the anandamide content of bladder tissues. A, A liquid chromatography-mass spectrometry chromatogram of a spiked control sample. The scan was set between $\mathrm{m} / \mathrm{z}=200$ and $\mathrm{m} / \mathrm{z}=600$. A major peak elutes at $6.173 \mathrm{~min}$, giving a mass ion of 348.3 , which represents the protonated molecular ion with $100 \%$ abundance (arrow). The molecular weight of anandamide is 347.3 . B, A liquid chromatography-mass spectrometry chromatogram of a sample from a naive bladder. Note that the size of the peak representing anandamide is negligible (arrow). C, A liquid chromatographymass spectrometry chromatogram of a sample from an inflamed bladder. Note that the peak representing anandamide (arrow) is significantly larger that that in B. D, Average anandamide content of control and inflamed bladders at different time points after intraperitoneal cyclophosphamide injection. Note that the anandamide content of inflamed bladders is significantly increased at either of the time points in comparison with that of naive bladders. ${ }^{*} p<0.05$. Error bars indicate SEM.
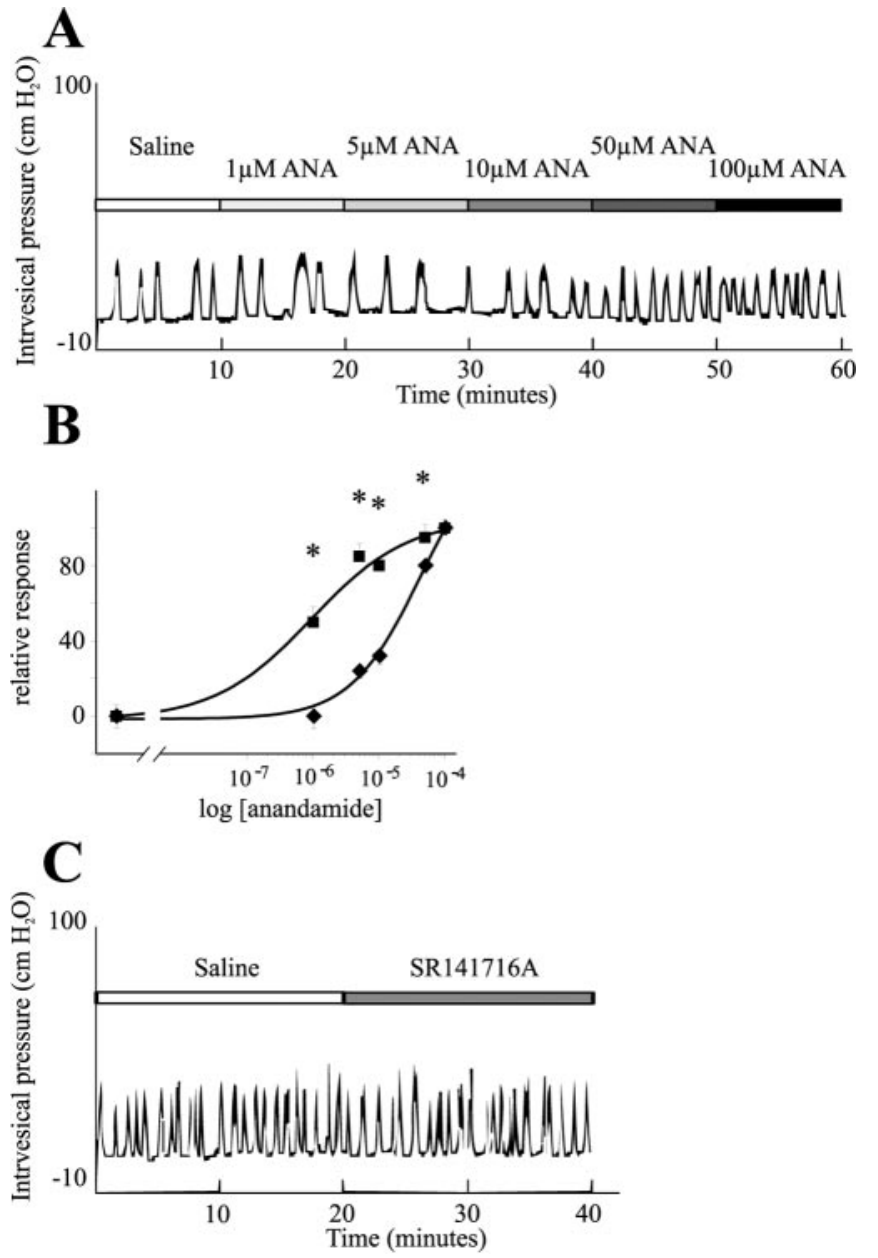

Figure 4. Effect of exogenous anandamide (ANA) on the reflex activity of naive bladders. A, A typical cystometrogram during cumulative application of anandamide (1-100 $\mu \mathrm{m})$ onto the serosal surface of a bladder. Note that only 50 and $100 \mu \mathrm{m}$ anandamide increased the bladder reflex activity. $B$, Dose-response relationship of anandamide on naive bladders in the absence ( ) or in the presence $(\square)$ of SR141716A, a cannabinoid 1 receptor antagonist. Note that the CB1 receptor antagonist significantly increased the potency of anandamide on the bladder. C, Whereas exogenous anandamide, in addition to TRPV1, seems to activate the CB1 receptor in naive bladders, endogenous anandamide during inflammation apparently does not induce any activity of the inhibitory receptor; 20 min superfusion of the CB1 receptor antagonist failed to increase the reflex activity of bladders from cyclophosphamide-injected rats. ${ }^{*} p<0.05$.

tion), whereas the second RTX application failed to increase the bladder activity ( 0.3 contractions/min during the $10 \mathrm{~min}$ wash before the second RTX application and 0.3 contractions $/ \mathrm{min}$ during the second RTX application).

To find out whether anandamide had a similar desensitizing effect, a 10 min saline and 10 min anandamide $(50 \mu \mathrm{M})$ application was followed by a $30 \mathrm{~min}$ wash with saline and another 10 min $50 \mu \mathrm{M}$ anandamide application. The first anandamide application increased the number of bladder contractions from $0.55 \pm$ 0.06 to $0.85 \pm 0.1$ contractions $/ \mathrm{min}(n=4)$ (Fig. $5 B, C)$. This value was similar to that found when $50 \mu \mathrm{M}$ anandamide was applied in a cumulative manner and was significantly different from the basal value ( $p=0.002$ ). The frequency of the bladder reflex contractions decreased gradually during the saline wash period and by $20 \mathrm{~min}$ reached a stable value $(0.4 \pm 0.14$ contractions/min; $n=4)$ (Fig. $5 B, C$ ), which was not significantly different from the basal activity of the bladders $(p=0.1)$. During the second anandamide application, the frequency of bladder contractions increased to $0.90 \pm 0.14$ contractions $/ \min (n=4)$ (Fig. 

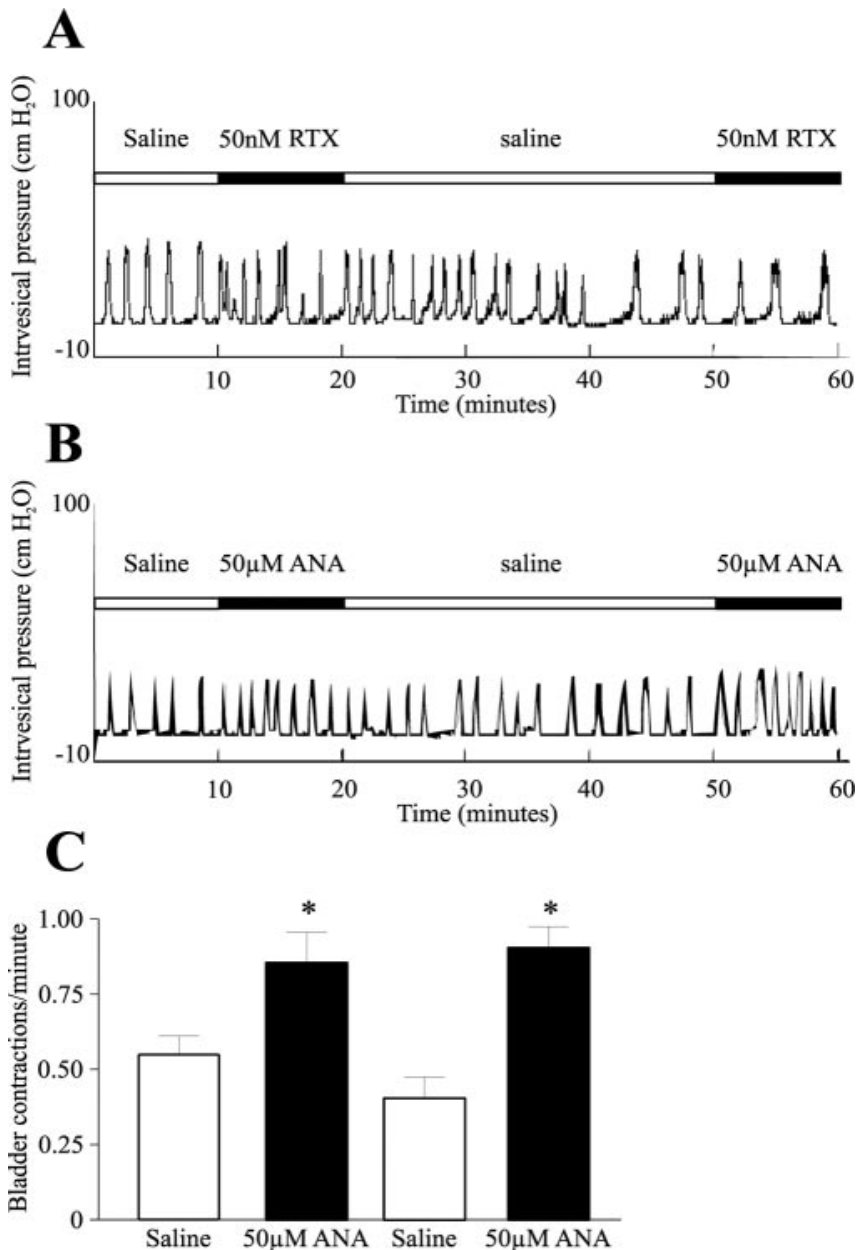

Figure 5. Whereas vanilloids, such as capsaicin or RTX, do induce desensitization, anandamide (ANA) does not induce desensitization of the reflex activity of the urinary bladder. $A$, First application of RTX onto the serosal surface of naive bladders increases the reflex activity. However, the second RTX activation fails to increase the number of contractions. B, A typical cystometrogram on a naive bladder. Both the first and the second anandamide superfusion enhanced the reflex activity significantly. Note that the increase in the reflex activity was similar during the first and second anandamide application. C, Average response of naive bladders to 50 $\mu \mathrm{M}$ anandamide (solid bars; $n=4$ ). Empty bars represent the number of contractions per minute during saline superfusion onto the serosal surface of bladders. ${ }^{*} p<0.05$. Error bars indicate SEM.

$5 B, C)$, which was significantly higher than the basal value ( $p=$ $0.005)$ and similar to that observed during the first anandamide application $(p=0.1)$.

To find out whether the anandamide-evoked increase in the bladder reflex activity was mediated through TRPV1, the basal bladder activity was determined in four rats, and $50 \mu \mathrm{M}$ anandamide was applied onto the bladders for $10 \mathrm{~min}$. Anandamide application increased the bladder activity from $0.48 \pm 0.01$ to $0.82 \pm 0.02$ contractions $/ \min (p=0.00003 ; n=4)$ (Fig. $6 A)$. This application was followed by saline wash for $30 \mathrm{~min}$, which reduced the number of bladder contractions to the control values $(0.47 \pm 0.16$ contractions $/ \mathrm{min})$. Next, bladders were exposed to $50 \mu \mathrm{M}$ capsazepine for $30 \mathrm{~min}$. In agreement with our previous observations, capsazepine did not change the bladder reflex activity (data not shown). Then, $50 \mu \mathrm{M}$ anandamide together with capsazepine $(50 \mu \mathrm{M})$ was applied onto the bladders. In the presence of capsazepine, anandamide failed to produce any increase in the frequency of bladder contractions $(0.41 \pm 0.03$ contractions/min; $p=0.1 ; n=4$ ) (Fig. $6 A$ ).

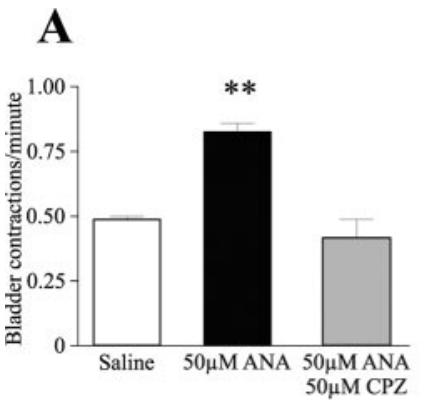

B

Figure 6. Anandamide (ANA) induces reflex activity in the bladder through TRPV1. A, Average response of naive bladders to anandamide $(50 \mu \mathrm{M})$ in the absence (solid black bar) or presence (50 $\mu \mathrm{m}$; solid gray bar) of capsazepine (CPZ). Capsazepine completely blocked the anandamide-induced reflex activity $(n=4)$. B, Desensitization of capsaicin-sensitive bladder afferents by intravesical RTX instillation also completely blocked the $50 \mu \mathrm{M}$ anandamide-evoked increase in bladder reflex activity (solid bar; $n=4$ ). Empty bars in both $A$ and $B$ represent the number of contractions during saline application. ${ }^{* *} p<0.05$. Error bars indicate SEM.

To further establish the involvement of TRPV1 in anandamideinduced bladder hyperreflexia, we applied $50 \mu \mathrm{M}$ anandamide onto bladders that had been desensitized with intravesical RTX instillation. The basal activity of the RTX-pretreated bladders $(0.5 \pm 0.07$ contractions/min; $n=4)$ (Fig. $6 B)$ was not different from that of the naive animals. In contrast to the results with naive rats, $50 \mu \mathrm{M}$ anandamide failed to produce any increase in the number of reflex contractions of these bladders $(0.48 \pm 0.07$ contractions/min; $n=4$ ) (Fig. $6 B$ ). Together, these findings indicated that exogenous anandamide increased the bladder reflex activity through TRPV1 and that anandamide did not produce long-term desensitization.

The effect of the CB1 receptor antagonist SR1411716A on the exogenous anandamide-evoked increase of reflex activity in naive bladders

Previous data show that TRPV1 and the CB1 receptor are coexpressed in some primary sensory neurons and visceral afferents (Ahluwalia et al., 2000, 2003b; MacNaughton et al., 2004). To find out whether in addition to TRPV1 activation, anandamide also activated the $\mathrm{CB} 1$ receptor in bladder afferents, the $\mathrm{CB} 1$ receptor antagonist SR141716A $(50 \mu \mathrm{M})$ was applied onto the bladders for $10 \mathrm{~min}$ after determining the basal bladder reflex activity. Anandamide $(1-100 \mu \mathrm{M})$ was then applied together with SR141716A $(50 \mu \mathrm{M})$ in a cumulative manner. The baseline bladder reflex activity in these experiments was $0.58 \pm 0.03$ contractions/min $(n=8)$ (Fig. $4 B)$. Administration of SR141716A alone had no effect on the bladder reflex activity $(0.6 \pm 0.04$ contractions/min; $n=8)$. However, the anandamide-evoked bladder activity was significantly enhanced by the CB1 receptor antagonist (Fig. $4 B$ ). The lowest concentration of anandamide producing a significant increase in the reflex activity in the presence of SR141716A was $1 \mu \mathrm{M}(0.69 \pm 0.05$ contractions/min; $p=0.006$; $n=8$ ) (Fig. $4 B$ ). Five micromolar anandamide produced an additional increase in the bladder reflex activity $(0.77 \pm 0.05 ; p=$ $0.0003 ; n=8$ ) (Fig. $4 B$ ). This value, however, was not significantly different from that produced by $1 \mu \mathrm{M}(p=0.1)$. No additional significant increase in the reflex activity could be evoked with 10,50 , or $100 \mu \mathrm{M}$ anandamide (Fig. 4 B). Comparison of the anandamide concentration-response curves on the bladder reflex activity in the absence or presence of the CB1 receptor antagonist revealed that $\mathrm{SR} 141716 \mathrm{~A}$ reduced the $\mathrm{EC}_{50}$ of anandamide from $17.8 \pm 2$ to $1.8 \pm 0.6 \mu \mathrm{M}(n=8)$. The difference between the 
$\mathrm{EC}_{50}$ values was significant ( $\left.p=0.001\right)$. These data clearly demonstrated that in addition to an action on TRPV1, anandamide also activated the $\mathrm{CB} 1$ receptor in the naive bladder, which reduces contractility.

\section{The effect of the CB1 receptor antagonist SR1411716A on reflex activity in inflamed bladders}

To find out whether anandamide produced during inflammation, or any other endogenous CB1 receptor ligand activated the CB1 receptor in inflamed bladders, we also superfused SR141716A to the bladders of three cyclophosphamide-injected rats. The average reflex activity of the bladders during saline application was $0.95 \pm 0.06$ contractions/min $(n=3)$ (Fig. $4 C)$. Twenty minute superfusion of SR141716A did not change the reflex activity of the bladder significantly $(0.93 \pm 0.05$ contractions/min; $n=3$ ) (Fig. 4C). These findings indicated that the CB1 receptor was not activated by endogenous anandamide or other CB1 receptor agonist in inflamed bladders.

\section{The effect of inhibition of anandamide hydrolysis on reflex activity in naive bladders}

To find out whether endogenous anandamide could also increase the number of bladder reflex contractions, the FAAH inhibitor PIA $(30 \mu \mathrm{M})$ was applied onto the serosal surface of naive bladders. After establishing the basal reflex activity in five animals $(0.42 \pm 0.04$ contractions $/ \mathrm{min}$ ) (Fig. $7 \mathrm{~A}, B)$, PIA was applied for $30 \mathrm{~min}$. Fifteen minutes after the beginning of PIA application, the frequency of bladder reflex contractions increased to $0.66 \pm$ 0.04 contractions/min $(p=0.002 ; n=6)$ (Fig. $7 A, B)$, which remained unchanged until the end of the drug administration. Washing the surface of the bladder with saline reduced the frequency of the reflex contractions to the basal value (data not shown).

To find out whether the PIA-evoked effect was mediated by TRPV1, $50 \mu \mathrm{M}$ capsazepine was applied onto the bladders for 10 min followed by a $30 \mathrm{~min}$ coapplication of $50 \mu \mathrm{M}$ capsazepine and $30 \mu \mathrm{M}$ PIA. The basal activity of these bladders was $0.38 \pm 0.03$ contractions/min $(n=5)$ (Figure $7 C)$. This value was not changed by capsazepine application (data not shown). In the presence of the TRPV1 antagonist, PIA failed to increase the number of reflex contractions of the bladder $(0.35 \pm 0.04$ contractions $/ \mathrm{min} ; p=0.1 ; n=5$ ) (Fig. 7C).

\section{The effect of inhibition of anandamide hydrolysis on reflex activity in inflamed bladders}

To find out whether elevating the level of endogenous anandamide by inhibiting its hydrolysis increases the reflex activity in inflamed bladders, we also applied PIA onto the serosal surface of bladders from four cyclophosphamide-injected rats. Soon after the beginning of PIA superfusion, the elevated activity seen in two of the four bladders ( 0.86 and 1.1 contractions/min) was further increased. One of these two bladders became tetanic during PIA application (from 1.1 contractions/min) (Fig. 7D), whereas the activity of the other increased from 0.86 to 1.2 contractions $/ \mathrm{min}$. The frequency of contractions in the other two bladders before PIA application was already 1.3 contractions/min, which seems to be the highest number of contractions possible in the model we used. PIA did not evoke any change in the activity of these bladders.

\section{The effect of anandamide instillation on spinal c-fos expression}

Immunohistochemical staining of the L6 spinal cord revealed that saline instillation into the bladder induced c-fos expression
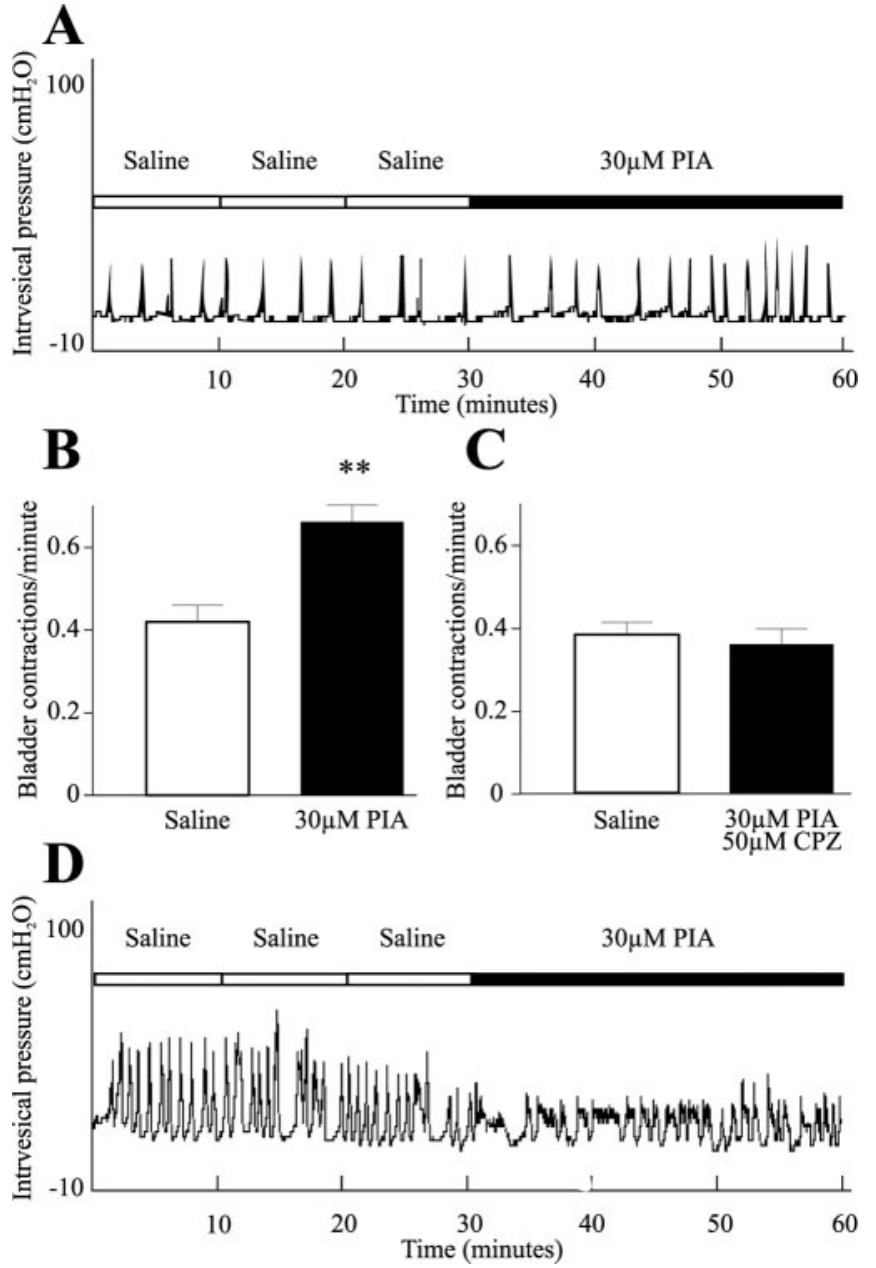

Figure 7. Blocking of anandamide hydrolysis with the fatty acid amide hydrolyze inhibitor PIA enhances the reflex activity both of naive bladders and inflamed bladders. $A$, A typical cystometrogram showing the effect of PIA on a naive bladder. Note that by about the 20th minute of PIA application, the reflex activity is increased and became stable. $B$, Average responses of naive bladders to PIA application (solid bar; $n=4$ ). The PIA-evoked increase in the reflex activity was significant. C, Capsazepine (CPZ; $50 \mu \mathrm{M})$ prevented the PIA-induced increase in bladder reflex activity (solid bar). Empty bars in both $B$ and ( show the number of contractions during saline application. D, PIA application also increased the activity of two of four inflamed bladders. One bladder became tetanic during PIA application. ${ }^{* *} p<0.05$. Error bars indicate SEM.

in $51.5 \pm 7.8$ cells per spinal cord section $(n=4)($ Fig. $8 A, C)$. Positive cells were distributed by three main areas, lamina I, intermediolateral gray matter, and dorsal commissure. Instillation of $50 \mu \mathrm{M}$ anandamide significantly increased the number of Fospositive neurons to $79.5 \pm 4.7$ cells per section $(p=0.003 ; n=4)$ (Fig. $8 B, C$ ). The spinal distribution was similar to that found in saline-instilled animals (Fig. $8 B$ ). Instillation of capsazepine $(50$ $\mu \mathrm{M})$ together with anandamide $(50 \mu \mathrm{M})$ completely prevented the anandamide-evoked increase in c-fos expression (51.2 \pm 5.3 ; $p=0.5 ; n=4)$ (Fig. 8C). Anandamide also failed to increase the number of Fos-immunoreactive neurons when it was instilled into the bladders of rats pretreated with RTX (Fig. 8C).

\section{Discussion}

In agreement with previous results, we found in the present study that intraperitoneal cyclophosphamide injection evoked hemorrhagic cystitis, accompanied by increased bladder reflex activity and spinal c-fos expression (Lecci et al., 1994b; Vizzard, 2000; 
A

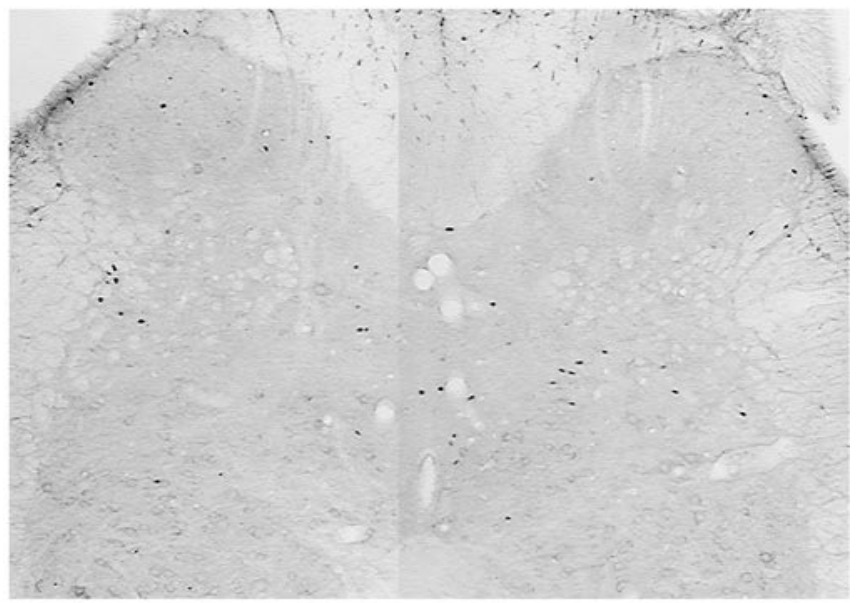

B
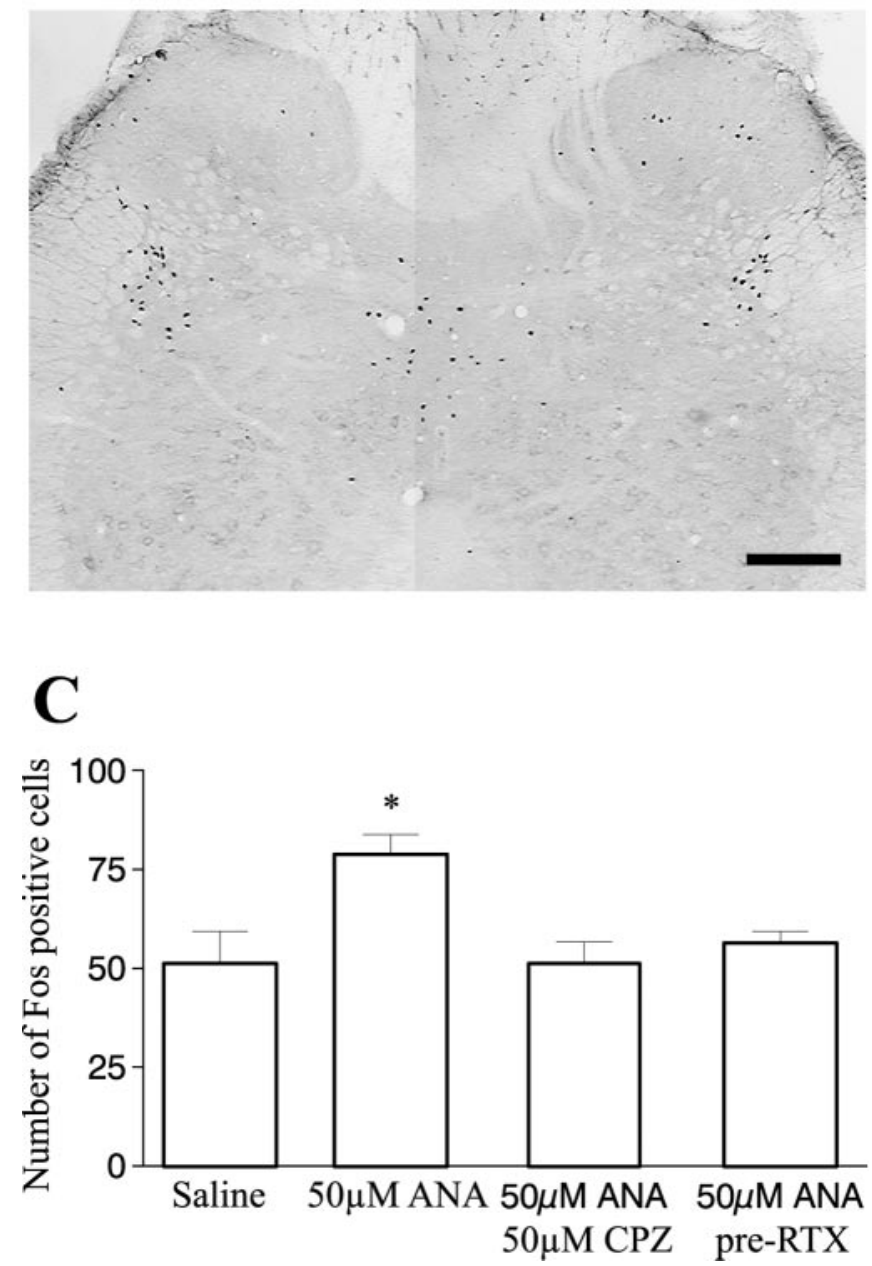

Figure 8. Intravesical instillation of anandamide (ANA) significantly increases spinal c-fos expression at the $\mathrm{L} 6$ segment. $A$, Representative section obtained $2 \mathrm{hr}$ after instillation of saline. $B$, Representative section obtained $2 \mathrm{hr}$ after $50 \mu \mathrm{m}$ anandamide. $C$, The anandamide-evoked effect was mediated by TRPV1 because either coapplication of $50 \mu \mathrm{m}$ capsazepine (CPZ) or intravesical RTX instillation $24 \mathrm{hr}$ before the anandamide instillation prevented the anandamide-evoked increase in the number of Fos-immunopositive cells. Scale bar, $100 \mu \mathrm{m}$. ${ }^{*} p<0.05$. Error bars indicate SEM.
Dinis et al., 2004). Our recent data that desensitization of capsaicinsensitive bladder afferents by intravesical RTX instillation blocked both the increased spinal c-fos expression and the enhanced bladder activity in cyclophosphamide-injected rats (Dinis et al., 2004) indicate that capsaicin-sensitive bladder afferents are involved in the development of cyclophosphamide-evoked bladder hyperactivity and hyperalgesia. The present finding that capsazepine significantly reduced the cyclophosphamide-evoked bladder hyperreflexia indicates that TRPV1 activity contributes to the activation of capsaicinsensitive bladder afferents in this cystitis model.

Capsazepine competes for the capsaicin binding site of TRPV1 (Bevan et al. 1992). Thus, during cyclophosphamideinduced cystitis, a compound(s) binding to that TRPV1 domain could be present in the bladder. Cyclophosphamide applied systemically induces cystitis through its metabolite, acrolein, that is excreted and thereby accumulates in the urine (Cox, 1979). Thus, TRPV1 could be activated by either of these compounds. However, our recordings show that neither cyclophosphamide nor acrolein evokes any current in TRPV1-expressing cells. The alternative possibility for TRPV1 activation after cyclophosphamide injection is that cyclophosphamide and/or acrolein induce the production of an endogenous TRPV1 ligand(s), which binds to the capsaicin-binding site of bladder afferents. Because previous findings suggested that anandamide could be produced in inflammatory conditions (Ahluwalia et al., 2003a; Linhart et al., 2003 ) and that anandamide seems to bind to the capsaicinbinding site (Jordt and Julius, 2002; Gavva et al., 2004), we studied the amount of this compound in bladder tissues. The finding that both the anandamide content of the tissues and the bladder reflex activity was significantly increased $4 \mathrm{hr}$ after the cyclophosphamide injection suggests that anandamide and bladder hyperreflexia could be causally related in cystitis. Although we did not measure bladder reflex activity at time points other than $4 \mathrm{hr}$ after injection, the findings that the anandamide content of the bladder tissues remained elevated up to $8 \mathrm{~d}$ after the first of the repeated cyclophosphamide injections and that prolonged cyclophosphamide-induced cystitis is also accompanied by bladder hyperreflexia (Lecci et al.,1994b; Dinis et al., 2004) support the assumed causal relationship between anandamide and inflammatory hyperreflexia.

If anandamide were responsible for the activation of TRPV1 in cyclophosphamide-induced cystitis, then it should replicate the hyperactivity and pain occurring in inflammation. Exogenous anandamide indeed increased the reflex activity and enhanced the spinal c-fos expression that has been used to indicate the transmission of nociceptive information to dorsal horn neurons (Hunt et al., 1987). However, the magnitude of the anandamide-evoked increase in the reflex activity and c-fos expression failed to reach those observed in cyclophosphamideinduced cystitis. The lowest concentration of anandamide that increased the bladder reflex activity significantly was $50 \mu \mathrm{M}$, which was higher than the minimal concentration of this compound activating TRPV1 in vitro (Zygmunt et al., 1999; Smart et al., 2000; Roberts et al., 2002; Ahluwalia et al., 2003b; Price et al., 2004). However, because of the diluting effects of the tissue fluids, direct comparisons of the concentrations used in vitro and in the present study are impossible. Nevertheless, the finding that both capsazepine and RTX pretreatment blocked the anandamideevoked increase both in the bladder activity and spinal c-fos expression suggests that both of these effects were mediated through TRPV1. The possibility that anandamide activated capsaicin-sensitive fibers through other mechanisms, such as activation of 5-hydroxytryptamine or NMDA receptors (Hampson 
et al., 1998; Kimura et al., 1998), seems unlikely because capsazepine probably cannot bind to these receptors (Bevan et al., 1992; Walpole et al., 1994).

Palmitoylisopropylamine also increased the reflex activity of naive bladders. This effect was inhibited by capsazepine, indicating that it was mediated by an endovanilloid(s) binding to the capsaicin-binding domain of TRPV1. Although we did not measure the anandamide content of bladders after PIA application, the finding that PIA inhibits the anandamide-hydrolyzing enzyme FAAH (Jonsson et al., 2001) suggests that that endovanilloid was anandamide. In agreement with the assumed role of anandamide in the development of inflammatory bladder hyperreflexia and the inhibitory action of PIA on FAAH, PIA also increased the activity of two of four inflamed bladders. The lack of effect of PIA on the other two inflamed bladders could be attributable to the apparent maximal activity of bladders before PIA application.

Repeated or long-lasting exposure of TRPV1 to vanilloids evokes TRPV1 desensitization, which results in unresponsiveness of bladders to repeated vanilloid agonist challenge (Szallasi, 2002). Anandamide can be responsible for the development of TRPV1-mediated inflammatory hyperalgesia and hyperreflexia only if it does not desensitize TRPV1. The findings that successive anandamide application increased the frequency of the reflex contractions to the same level and that the increase in frequency was maintained with prolonged anandamide application are in agreement with previous findings (Premkumar and Ahern, 2000; Ahluwalia et al., 2003b) that anandamide lacks desensitizing effects on TRPV1. This difference between capsaicin or RTX and anandamide might be attributable to different allosteric modifications in TRPV1 by the different ligands.

The CB1 receptor antagonist SR141716A significantly enhanced the excitatory potency of anandamide in naive bladders, indicating that in addition to TRPV1-mediated excitation, anandamide also evokes CB1 receptor-mediated inhibition in the bladder. The underlying mechanism of the SR141716A-evoked effect is not clear. However, it is an appealing possibility that the SR141716A-evoked effect was produced by blocking the CB1 receptor activation-evoked inhibition on bladder afferents coexpressing the CB1 receptor and TRPV1. This assumption is supported by previous data that a significant proportion of TRPV1expressing primary sensory neurons express the CB1 receptor and that anandamide evokes both TRPV1-mediated excitation and $\mathrm{CB} 1$ receptor-mediated inhibition in those cells (Ahluwalia et al., 2000, 2003b). The recent data of MacNaughton et al. (2004) that TRPV1 and the CB1 receptor are coexpressed by paravascular nerves and nerve fibers in submucosal ganglia in the ileum also support this assumption.

Interestingly, however, the CB1 receptor antagonist had no effect on inflamed bladders, suggesting that inflammatory processes might inhibit the effects of $\mathrm{CB} 1$ receptor agonists. Previous data support this assumption, because both PKA and PKC, which are activated in inflammation (Malmberg et al., 1997; Zhou et al., 2003), induce phosphorylation of the CB1 receptor, which results in reduced CB1 receptor activity (Garcia et al., 1998; Huang et al., 2002). Because both PKA and PKC increase both the potency and efficacy of anandamide on TRPV1 (Premkumar and Ahern, 2000; De Petrocellis et al., 2001), anandamide could excite capsaicin-sensitive bladder afferents in inflammatory conditions at a significantly lower concentration than we observed in the present study on naive bladders.

Recent findings that $\mathrm{Ca}^{2+}$ influx into capsaicin-sensitive primary sensory neurons results in anandamide production indicate that in addition to macrophages and vascular endothelial cells, capsaicin-sensitive bladder afferents could also be the source of anandamide activating TRPV1 in cystitis (Di Marzo et al., 1996; Kuwae et al., 1999; Zygmunt et al., 1999; Ahluwalia et al., 2003a). Acrolein evokes the production of inflammatory mediators in the bladder (Ahluwalia et al., 1994), which induce $\mathrm{Ca}^{2+}$ influx into primary sensory neurons (Linhart et al., 2003) and thus probably stimulate anandamide production in bladder afferents. However, increased anandamide concentration in the bladder could also be attributable to decreased anandamide hydrolysis by FAAH in bladder tissues. Whatever the underlying mechanism, the inflammation-induced increase in the anandamide content of the whole bladder was modest. Nevertheless, as mentioned, the concentration of anandamide produced by capsaicinsensitive primary sensory neurons after $\mathrm{Ca}^{2+}$ influx is comparable with that evoking TRPV1-mediated excitation when inflammatory conditions are simulated in cultures (Ahluwalia et al., 2003a,b). Thus, if anandamide production in capsaicinsensitive bladder afferents were responsible for the increased anandamide content in bladder tissues in cystitis, the local concentration of anandamide at TRPV1 could be high enough to open the ion channel.

In summary, our present findings show that (1) the anandamide content is increased in the bladder during cyclophosphamideinduced cystitis, (2) exogenous anandamide increases bladder reflex activity and spinal c-fos expression in a TRPV1-dependent manner, (3) anandamide does not induce desensitization of TRPV1, (4) endogenous anandamide enhances bladder reflex activity in a TRPV1-dependent manner, and (5) both the exogenous and endogenous anandamide-evoked effects resemble to those occurring in cystitis. These findings suggest that anandamide contributes to TRPV1 activation and to the development of pain and hyperactivity of the bladder in inflammation. Because at present no drug is available to either block the synthesis (Schmid, 2000) or increase the degradation of endogenous anandamide (Giang and Cravatt, 1997), ultimate proof for the role of anandamide in the development of inflammatory bladder pain and hyperreflexia cannot be provided. Nevertheless, recent findings show that ileitis is also accompanied by increased anandamide production and that exogenous anandamide evokes ileitis and plasma extravasation in the intestine by a TRPV1-dependent mechanism (McVey et al., 2003). Although, McVey et al. (2003) did not study the effect of anandamide on intestinal motility and hyperalgesia, these findings strongly support the putative role of anandamide in the development of visceral inflammatory hyperreflexia and hyperalgesia.

\section{References}

Ahluwalia A, Maggi CA, Santicioli P, Lecci A, Giuliani S (1994) Characterization of the capsaicin-sensitive component of cyclophosphamideinduced inflammation in the rat urinary bladder. Br J Pharmacol 111:1017-1022.

Ahluwalia J, Urban L, Capogna M, Bevan S, Nagy I (2000) Cannabinoid 1 receptors are expressed in nociceptive primary sensory neurons. Neuroscience 100:685-688

Ahluwalia J, Yaqoob M, Urban L, Bevan S, Nagy I (2003a) Activation of capsaicin-sensitive primary sensory neurones induces anandamide production and release. J Neurochem 84:585-591.

Ahluwalia J, Urban L, Bevan S, Nagy I (2003b) Anandamide regulates neuropeptide release from capsaicin-sensitive primary sensory neurons by activating both the cannabinoid 1 receptor and the vanilloid receptor 1 in vitro. Eur J Neurosci 17:2611-2618.

Akerman S, Kaube H, Goadsby PJ (2004) Anandamide is able to inhibit trigeminal neurons using an in vivo model of trigeminovascularmediated nociception. J Pharmacol Exp Ther 309:56-63. 
Avelino A, Cruz F, Coimbra A (1999) Intravesical resiniferatoxin desensitizes rat bladder sensory fibres without causing intense noxious excitation. A c-fos study. Eur J Pharmacol 378:17-22.

Avelino A, Cruz C, Nagy I, Cruz F (2002) Vanilloid receptor 1 expression in the rat urinary tract. Neuroscience 109:787-798.

Avelino A, Dinis P, Charrua A, Nagy I, Yacoob M, Cruz F (2003) The endogenous TRPV1 ligand anandamide increases in the rat inflamed urinary bladder and may contribute to inflammatory pain. Soc Neurosci Abstr 29:608.3.

Bevan S, Hothi S, Hughes G, James IF, Rang HP, Shah K, Walpole CS, Yeats JC (1992) Capsazepine: a competitive antagonist of the sensory neurone excitant capsaicin. Br J Pharmacol 107:544-552.

Caterina MJ, Schumacher MA, Tominaga M, Rosen TA, Levine JD, Julius D (1997) The capsaicin receptor: a heat-activated ion channel in the pain pathway. Nature 389:816-824.

Caterina MJ, Leffler A, Malmberg AB, Martin WJ, Trafton J, Petersen-Zeitz KR, Koltzenburg M, Basbaum AI, Julius D (2000) Impaired nociception and pain sensation in mice lacking the capsaicin receptor. Science 288:306-313.

Chuang HH, Prescott ED, Kong H, Shields S, Jordt SE, Basbaum AI, Chao MV, Julius D (2001) Bradykinin and nerve growth factor release the capsaicin receptor from PtdIns(4,5)P2-mediated inhibition. Nature 411:957-962.

Cox PJ (1979) Cyclophosphamide cystitis-identification of acroleine as the causative agent. Biochem Pharmacol 28:2045-2049.

Davis JB, Gray J, Gunthorpe MJ, Davey PT, Overend P, Harries MH, Latcham J, Clapham C, Atkinson K, Rance K, Grau E, Harper AJ, Pugh PL, Rogers DC, Bingham S, Sheardown SA (2000) Vanilloid receptor-1 is essential for inflammatory thermal hyperalgesia. Nature 405:183-187.

De Petrocellis L, Harrison S, Bisogno T, Tognetto M, Brandi I, Smith GD, Creminon C, Davis JB, Geppetti P, Di Marzo V (2001) The vanilloid receptor (VR1)-mediated effects of anandamide are potently enhanced by the cAMP-dependent protein kinase. J Neurochem 2001 77:1660-1663.

Devane WA, Hanus L, Breuer A, Pertwee RG, Stevenson LA, Griffin G, Gibson D, Mandelbaum A, Etinger A, Mechoulam R (1992) Isolation and structure of a brain constituent that binds to the cannabinoid receptor. Science 258:1946-1949.

Di Marzo V, De Petrocellis L, Sepe N, Buono A (1996) Biosynthesis of anandamide and related acylethanolamides in mouse J774 macrophages and N18 neuroblastoma cells. Biochem J 316:977-984.

Dinis P, Charrua A, Avelino A, Cruz F (2004) Intravesical resiniferatoxin decreases spinal c-fos expression and increases bladder volume to reflex micturition in rats with chronic inflamed urinary bladders. BJU Int 94:153-157.

Evans RM, Scott RH, Ross RA (2004) Multiple actions of anandamide on neonatal rat cultured sensory neurones. Br J Pharmacol 141:1223-1233.

Garcia DE, Brown S, Hille B, Mackie K (1998) Protein kinase C disrupts cannabinoid actions by phosphorylation of the CB1 cannabinoid receptor. J Neurosci 18:2834-2841.

Gavva NR, Klionsky L, Qu Y, Shi L, Tamir R, Edenson S, Zhang TJ, Viswanadhan VN, Toth A, Pearce LV, Vanderah TW, Porreca F, Blumberg PM, Lile J, Sun Y, Wild K, Louis JC, Treanor JJ (2004) Molecular determinants of vanilloid sensitivity in TRPV1. J Biol Chem 279:20283-20295.

Giang DK, Cravatt BF (1997) Molecular characterization of human and mouse fatty acid amide hydrolases. Proc Natl Acad Sci USA 94:2238-2242.

Guo A, Vulchanova L, Wang J, Li X, Elde R (1999) Immunocytochemical localization of the vanilloid receptor 1 (VR1): relationship to neuropeptides, the P2X3 purinoceptor and IB4 binding sites. Eur J Neurosci 11:946-958.

Hampson AJ, Bornheim LM, Scanziani M, Yost CS, Gray AT, Hansen BM, Leonoudakis DJ, Bickler PE (1998) Dual effects of anandamide on NMDA receptor-mediated responses and neurotransmission. J Neurochem 70:671-676.

Huang CC, Chen YL, Lo SW, Hsu KS (2002) Activation of cAMPdependent protein kinase suppresses the presynaptic cannabinoid inhibition of glutamatergic transmission at corticostriatal synapses. Mol Pharmacol 61:578-585.
Hunt SP, Mantyh PW (2001) The molecular dynamics of pain control. Nat Rev Neurosci 2:83-91.

Hunt SP, Pini A, Evan G (1987) Induction of c-fos-like protein in spinal cord neurons following sensory stimulation. Nature 328:632-634.

Ishizuka O, Igawa Y, Mattiasson A, Andersson KE (1994) Capsaicininduced bladder hyperactivity in normal conscious rats. J Urol 152:525-530.

Jonsson KO, Vandevoorde S, Lambert DM, Tiger G, Fowler CJ (2001) Effects of homologues and analogues of palmitoylethanolamide upon the inactivation of the endocannabinoid anandamide. Br J Pharmacol 133:1263-1275

Jordt SE, Julius D (2002) Molecular basis for species-specific sensitivity to "hot" chili peppers. Cell 108:421-430.

Kimura T, Ohta T, Watanabe K, Yoshimura H, Yamamoto I (1998) Anandamide, an endogenous cannabinoid receptor ligand, also interacts with 5-hydroxytryptamine (5-HT) receptor. Biol Pharm Bull 21:224-226.

Kollarik M, Undem BJ (2004) Activation of bronchopulmonary vagal afferent nerves with bradykinin, acid and vanilloid receptor agonists in wildtype and TRPV1-/- mice. J Physiol (Lond) 555:115-123.

Kuwae T, Shiota Y, Schmid PC, Krebsbach R, Schmid HO (1999) Biosynthesis and turnover of anandamide and other $\mathrm{N}$-acylethanolamines in peritoneal macrophages. FEBS Lett 459:123-127.

Laird JM, Olivar T, Roza C, De Felipe C, Hunt SP, Cervero F (2000) Deficits in visceral pain and hyperalgesia of mice with a disruption of the tachykinin NK1 receptor gene. Neuroscience 98:345-352.

Lecci A, Giuliani S, Meini S, Maggi CA (1994a) In vivo effects of neurokinin $\mathrm{B}$ on rat urinary bladder motility: involvement of tachykinin NK1 and NK2 receptors. Neuropeptides 27:53-62.

Lecci A, Giuliani S, Santicioli P, Maggi CA (1994b) Involvement of spinal tachykinin NK1 and NK2 receptors in detrusor hyperreflexia during chemical cystitis in anaesthetized rats. Eur J Pharmacol 259:129-135.

Linhart O, Obreja O, Kress M (2003) The inflammatory mediators serotonin, prostaglandin E2 and bradykinin evoke calcium influx in rat sensory neurons. Neuroscience 118:69-74.

Lu W, Haber SN (1992) In situ hybridization histochemistry: a new method for processing material stored for several years. Brain Res 578:155-160.

MacNaughton WK, Van Sickle MD, Keenan CM, Cushing K, Mackie K, Sharkey KA (2004) Distribution and function of the cannabinoid-1 receptor in the modulation of ion transport in the guinea pig ileum: relationship to capsaicin-sensitive nerves. Am J Physiol Gastrointest Liver Physiol 286:G863-G871.

Malmberg AB, Brandon EP, Idzerda RL, Liu H, McKnight GS, Basbaum AI (1997) Diminished inflammation and nociceptive pain with preservation of neuropathic pain in mice with a targeted mutation of the type I regulatory subunit of cAMP-dependent protein kinase. J Neurosci 17:7462-7470.

McIntyre P, McLatchie LM, Chambers A, Phillips E, Clarke M, Savidge J, Toms C, Peacock M, Shah K, Winter J, Weerasakera N, Webb M, Rang HP, Bevan S, James IF (2001) Pharmacological differences between the human and rat vanilloid receptor 1 (VR1). Br J Pharmacol 132:1084-1094.

McVey DC, Schmid PC, Schmid H, Vigna SR (2003) Endocannabinoids induce ileitis in rats via the capsaicin receptor (VR1). J Pharmacol Exp Ther 304:713-722.

Premkumar LS, Ahern GP (2000) Induction of vanilloid receptor channel activity by protein kinase C. Nature 408:985-990.

Price TJ, Patwardhan A, Akopian AN, Hargreaves KM, Flores CM (2004) Modulation of trigeminal sensory neuron activity by the dual cannabinoid-vanilloid agonists anandamide, $N$-arachidonoyl-dopamine and arachidonyl-2-chloroethylamide. Br J Pharmacol 141:1118-1130.

Richardson JD, Kilo S, Kenneth M, and Hargreaves KM (1998) Cannabinoids reduce hyperalgesia and inflammation via interaction with peripheral $\mathrm{CB}_{1}$ receptors. Pain 75:111-119.

Roberts LA, Christie MJ, Connor M (2002) Anandamide is a partial agonist at native vanilloid receptors in acutely isolated mouse trigeminal sensory neurons. Br J Pharmacol 137:421-428.

Schmelz M, Schmid R, Handwerker HO, Torebjork HE (2000) Encoding of burning pain from capsaicin-treated human skin in two categories of unmyelinated nerve fibres. Brain 123:560-571.

Schmid HH (2000) Pathways and mechanisms of $N$-acylethanolamine bio- 
synthesis: can anandamide be generated selectively? Chem Phys Lipids 108:71-87.

Smart D, Gunthorpe MJ, Jerman JC, Nasir S, Gray J, Muir AI, Chambers JK, Randall AD, Davis JB (2000) The endogenous lipid anandamide is a full agonist at the human vanilloid receptor (hVR1). Br J Pharmacol 129:227-230

Szallasi A (2002) Vanilloid (capsaicin) receptors in health and disease. Am J Clin Pathol 118:110-121.

Szolcsanyi J (1977) A pharmacological approach to elucidation of the role of different nerve fibres and receptor endings in mediation of pain. J Physiol (Paris) 73:251-279.

Vizzard MA (2000) Alterations in spinal cord Fos protein expression in- duced by bladder stimulation following cystitis. Am J Physiol Regul Integr Comp Physiol 278:R1027-R1039.

Walpole CS, Bevan S, Bovermann G, Boelsterli JJ, Breckenridge R, Davies JW, Hughes GA, James I, Oberer L, Winter J, Wriglessworth R (1994) The discovery of capsazepine, the first competitive antagonist of the sensory neuron excitants capsaicin and resiniferatoxin. J Med Chem 37:1942-1954.

Zhou Y, Li GD, Zhao ZQ (2003) State-dependent phosphorylation of epsilon-isozyme of protein kinase $\mathrm{C}$ in adult rat dorsal root ganglia after inflammation and nerve injury. J Neurochem 85:571-580.

Zygmunt PM, Petersson J, Andersson D, Chuang H, Sorgard M, Di Marzo V, Julius D, Hogestatt ED (1999) Vanilloid receptors on sensory nerves mediate the vasodilator action of anandamide. Nature 400:452-457. 